\title{
Recurrent Malignant Mesothelioma
}

National Cancer Institute

\section{Source}

National Cancer Institute. Recurrent Malignant Mesothelioma. NCI Thesaurus. Code C7866.

The reemergence of malignant mesothelioma after a period of remission 